\title{
Some advances on essential spectra of one sided operator matrix with application
}

\author{
Marwa Belghith ${ }^{1}$, Nedra Moalla ${ }^{1}$, and Ines Walha ${ }^{1}$ \\ ${ }^{1}$ University of Sfax Faculty of Sciences of Sfax
}

January 17, 2021

\begin{abstract}
This paper deals with a new description of the one sided operator matrix form, as a generalization of the case of the unbounded operator matrix with the non diagonal domain, to investigate some advances in the analysis of some essential spectra under weaker hypotheses then the one provided in the works of $[17,33]$. An example of differential equations is tested to ensure the validity of the abstract results.
\end{abstract}

\section{Hosted file}

MMAS2021.pdf available at https://authorea.com/users/389871/articles/504397-some-advanceson-essential-spectra-of-one-sided-operator-matrix-with-application 